\title{
Use of Evidence in Acute Stroke Decision-Making: Implications for Evidence-Based Medicine
}

\author{
Timothe Langlois-Therien ${ }^{1}$, Brian Dewar ${ }^{1}$, Ross Upshur ${ }^{2}$, and Michel Shamy ${ }^{1}$ \\ ${ }^{1}$ Ottawa Hospital Research Institute \\ ${ }^{2}$ University of Toronto Dalla Lana School of Public Health
}

April 16, 2021

\begin{abstract}
Evidence-Based Medicine proposes a prescriptive model of physician decision-making in which "best evidence" is used to guide best practice. And yet, proponents of EBM acknowledge that EBM fails to offer a systematic theory of physician decisionmaking. In this paper, we explore how physicians from the neurology and emergency medicine communities have responded to an evolving body of evidence surrounding the acute treatment of patients with ischemic stroke. Through analysis of this case study, we argue that EBM's vision of evidence-based medical decision-making fails to appreciate a process that we have termed epistemic evaluation. Namely, physicians are required to interpret and apply any knowledge - even what EBM would term "best evidence" - in light of their own knowledge, background and experience. This is consequential for EBM as understanding what physicians do and why they do it would appear to be essential to achieving optimal practice in accordance with best evidence.
\end{abstract}

\section{Hosted file}

Main document.pdf available at https://authorea.com/users/408254/articles/518333-use-ofevidence-in-acute-stroke-decision-making-implications-for-evidence-based-medicine 